\title{
PENDEKATAN PEMBELAJARAN RISET PENDIDIKAN LINGKUNGAN
}

\author{
Fahrudi Ahwan Ikhsan ${ }^{1}$, Fahmi Arif Kurnianto², Bejo Apriyanto ${ }^{3}$, \\ Elan Artono Nurdin ${ }^{4}$ \\ Program Studi Pendidikan Geografi, Universitas Jember, Indonesia. \\ Jalan Kalimantan Nomor 37 Jember
}

\begin{abstract}
Abstrak: Penelitian ini bertujuan untuk menyelidiki pengaruh pembelajaran riset terhadap sikap peduli lingkungan mahasiswa. Penelitian dilakukan terhadap mahasiswa yang mengikuti program pendidikan lingkungan, perubahan sikap lingkungan dilakukan dengan mengembangkan pembelajaran riset. Metode yang digunakan dalam penelitian ini adalah mixed methods kuantitatif dan kualitatif. Mahasiswa diberikan informasi konsep dan degradasi lingkungan serta pembelajaran riset, mahasiswa membuat kelompok dan menyusun proposal sesuai tema kajian. Mahasiswa melakukan penelitian untuk pengumpulan data serta informasi yang kemudian disajikan dalam bentuk infomasi baik laporan dan artikel ilmiah. Pembelajaran riset disajikan dengan tujuan mengembangkan berpikir ilmiah mahasiswa. Hasil penelitian menunjukkan tidak ada perbedaan gender terhadap sikap peduli lingkungan karena pembelajaran riset memiliki dampak yang positif. Mahasiswa memberikan peningkatan kreativitas, pengetahuan. manfaat, dan berpikir kritis mahasiswa melalui kegiatan penelitian, diskusi, dan brainstorming. Praktik pembelajaran riset lebih membantu dalam mendeskripsikan permasalahan lingkungan dan pengambilan solusi terbaik bagi mahasiswa.
\end{abstract}

Kata kunci: Pembelajaran Riset, pendidikan lingkungan, sikap lingkungan, permasalahan dan solusi lingkungan

\section{A. PENDAHULUAN}

Lingkungan merupakan tempat makhluk hidup berinteraksi selama hidupnya. Lingkungan elemen yang mempengaruhi keseimbangan alam dan manusia. Keseimbangan negatif akan memberikan dampak buruk terhadap daya dukung lingkungan. Watson dan Halse (2005), menjelaskan semua aktivitas manusia dapat mempengaruhi permasalahan lingkungan. Pendidikan menjadi elemen kunci dalam mencegah dan menyelesaikan permasalahan lingkungan (Taskin, 2005, Oweini \& Houri, 2006). Pendidikan lingkungan akan membantu mahasiswa dalam mengembangkan keterampilan dan etika memahami hubungan manusia dengan lingkungan. Fokus pengalaman hidup mahasiswa membutuhkan tingkat partisipasi yang tinggi pada umumnya dalam pendidikan lingkungan hidup (Daskolia, Dimos, \& Kampylis, 2012). Permasalahan yang kontekstual diperlukan dalam membangun sistem kompetensi sebagai bahan kajian dalam perkuliahan. Kadji (2002) menjelaskan pengajaran integratif didasarkan pada filosofi dan kepraktisan. Aplikasi pembelajaran untuk mahasiswa pada 
umumnya mencakup ranah pengetahuan, keterampilan, sikap, dan nilai sebagai subjek dalam pengembangan pemahaman gagasan tentang permasalahan lingkungan. Baxte dan Jack (2008), memaparkan keuntungan penggunaan pembelajaran integratif akan memberikan pemahaman yang holistik kepada mahasiswa tentang keragaman pengetahuan dan pengalaman sebelumnya secara nyata. Drake (2004), mengganggap pendekatan pengajaran integrasi menjadi jalur nyata dalam pendidikan abad ini karena menghubungkan dengan situasi kehidupan nyata. Pertumbuhan kesadaran lingkungan menggambarkan kebutuhan skema pendidikan lingkungan yang efektif melahirkan cara berpikir baru (Markaki, 2014).

\section{Perkembangan}

kesadaran

lingkungan memberikan pengaruh terhadap karakter mahasiswa. Sikap peduli lingkungan dipengaruhi oleh faktor ekonomi, sikap orang tua, dan tempat tinggal (Rickinson, 2001). Aplikasi dari pendidikan lingkungan harus memberikan pemahaman pengetahuan, sikap, dan perilaku lingkungan secara berkelanjutan. Pendidikan lingkungan penting bagi calon guru nantinya untuk mengembangkan sikap peduli lingkungan pada semua jenjang pendidikan dasar dan menengah. May (2000), menjelaskan bahwa pendidikan lingkungan membutuhkan elemen seperti: dukungan administratif, anggaran, waktu, guru, masyarakat, silabus, program, pembelajaran kooperatif, dan tingkat pembelajaran umum yang fleksibel. Barnett, Vaughn, Strauss, \& Cotter (2011), keterlibatan mahasiswa menjadi bentuk evaluasi untuk manfaat ekologi, ekonomi, dan sosial dari perubahan ruang hijau perkotaan yang berpengaruh pada ekosistem daya dukung lingkungan. Investigasi permasalahan lingkungan dapat meingkatkan pemahaman berpikir dan observasi ilmiah dari mahasiswa. Aplikasi keterampilan berpikir dapat meningkatkan pembelajaran sains dan pendidikan lingkungan (Balim, 2013).

Program pendidikan lingkungan harus dipersiapkan bagi calon guru untuk semua bidang ilmu pengetahuan. Perilaku peduli dan berperan dalam menyelesaikan masalah secara aktif menjadi program penting bagi calon pendidik. Shepardson, Wee, Priddy, \& Harbor (2007), memaparkan bahwa pengalaman pendidikan memiliki dampak secara konseptual dalam membangun mental untuk peduli lingkungan secara kontekstual. Pembelajaran berbasis masalah salah satu yang diyakini dapat meningkatkan pengetahuan, sikap, perilaku, dan wawasan lingkungan bagi calon guru (Kilinc, 2010). Permasalahan yang dipecahkan tidak ada jawaban benar 
atau salah, tetapi dalam bentuk solusi yang masuk akal untuk mengatasai masalah (Hmelo-Silver \& Barrows, 2006). Isu permasalahan lingkungan dan perubahan iklim menjadi penting untuk dipecahkan oleh mahasiswa melalui pendekatan pembelajaran riset untuk pendidikan lingkungan.

Pembelajaran riset merupakan pendekatan konstruktivisme yang membutuhkan kelas atau kelompok kecil dari mahasiswa agar dapat bertanggung jawab dengan keputusannya. Pendekatan konstruktivisme memberikan kesempatan kepada mahasiswa untuk menghubungkan sains dengan isu-isu dunia nyata (CetinDindar, 2016). Pendekatan pembelajaran riset banyak memberikan reformasi sistem perkuliahan di universitas dalam menanamkan pengetahuan dan kemampuan analisis bagi calon guru. Peningkatan prestasi akademik memberikan keleluasaan belajar secara mandiri dalam membangun pengetahuan (Blackmore and Fraser, 2007). Kemampuan ini sangat penting untuk pendidikan di abad ke-21 (Brew, 2010). Pembelajaran riset bersifat interaktif dalam aplikasinya dengan kegiatan praktek, survei, dan belajar mandiri yang menumbuhkan komunikasi calon guru dan dosen (Liu \& Li, 2011). Kegiatan pembelajaran dan riset berperan bagi mahasiswa dalam memahami metodologi kerja lapangan, data penelitian, serta teori pendukung yang menjadi aspek perkembangan emosi dan intelektual di lapangan (Guinness, 2012). Hasil studi Srikoon, dkk (2013), di Thailand menunjukkan bahwa pembelajaran riset dapat meningkatkan penelitian, penemuan pengetahuan, dan keterampilan kerja yang berpengaruh terhadap prestasi, pola berpikir, keterampilan memecahkan masalah, berpikir kritis, sikap, dan menjadi dasar penelitian bagi mahasiswa. Pembelajaran riset bertujuan membantu calon guru dalam memperoleh informasi, pengetahuan,, keterampilan, dan sikap untuk pembangunan lingkungan yang berkelanjutan. Metode aplikasi pendidikan berkelanjutan menjadi penting dalam pendidikan lingkungan. Oleh karena itu, penelitian ini bertujuan untuk menentukan bagaimana penggunaan pendekatan pembelajaran riset dapat mempengaruhi sikap peduli lingkungan bagi calon guru secara berkelanjutan.

\section{B. METODE}

Penelitian ini digunakan untuk menginvestigasi pengaruh pembelajaran riset terhadap sikap kepedulian lingkungan calon guru menggunakan metode kuantitatif dan kualitatif dengan cara campuran. Penelitian campuran mencakup data kuantitatif dan kualitatif yang menjadi dasar analisis studi atau menganalisis dan menafsirkan data 
(Fraenkel, Wallen, \& Hyun, 2012; Leech \& Onwuegbuzie, 2009; Teddlie \& Yu, 2007). Desain eksplanasi digunakan dalam penelitian ini untuk menyempurnakan hasil uji coba. Peneliti melakukan kegiatan pertama kali pengambilan data kuantitatif kemudian diperbaiki dengan metode kualitatif (Creswell, 2009).

Teknik pengumpulan data kuantitatif menggunakan skala sikap lingkungan (EAS) (Barberoglu \& Tosonoglu, 1995). Instrumen pertanyaan berisi tentang sikap lingkungan (EAS) untuk pengumpulan data sikap lingkungan mahasiswa. Pengumpulan data kualitatif menggunakan menggunakan intrument wawancara semi struktur untuk mahasiswa. Instrumen yang diberikan berisi tiga pertanyaan terbuka dan tujuh pertanyaan dengan jawaban ya atau tidak tentang pendidikan lingkungan. Hasil wawancara digunakan untuk medukung analisis data kuantitatif skala sikap lingkungan (EAS).

Sikap lingkungan mencakup 21 indikator yang dikembangkan Berberoglu dan Tosunoglu (1994) untuk menganalisis sikap lingkungan mahasiswa dalam penelitian ini. Skala yang digunakan adalah skala likert dengan ketentuan yaitu skala (5) sangat setuju; (4) setuju; (3) ragu-ragu; (2) tidak setuju; (1) sangat tidak setuju. Konsistensi internal sikap lingkungan (EAS) yang dikembangkan dan dilaporkan Berberoglu dan Tosunoglu sebesar 0,77. Nilai alfa cronbach yang ditemukan dalam penelitian ini adalah 0,82 .

Subjek dalam penelitian ini adalah mahasiswa yang memprogram matakuliah pendidikan lingkungan di Fakultas Keguruan dan Ilmu Pendidikan Universitas Jember. Jumlah kelompok yang diinvestigasi sebanyak 39 kelompok mahasiswa.

Pelaksanaan perkuliahan diberikan kepada mahasiswa konsep dan degradasi lingkungan untuk 2 minggu pertama dengan durasi waktu 2 jam setiap minggu. Pertemuan ke 3 mahasiswa diberitahu tentang pembelajaran riset untuk investigasi isu permasalahan lingkungan. Mahasiswa dibagi menjadi 8 kelompok dengan tugas melakukan penelitian dan menyusun laporan sesuai isu masalah lingkungan yang sudah ditentukan. Hasil belajar tentang konsep dan degradasi lingkungan. Implementasi tahapan penelitian, mahasiswa mengatur rencana penelitian, waktu, dan laporan sesuai waktu yang ditetapkan dalam silabus dan rencana perkuliahan pendidikan lingkungan. Tahapan implementasi peembelajaran riset pendidikan lingkungan diuraikan pada tabel 1.

Pembagian topik pembelajaran riset isu masalah lingkungan untuk setiap kelompok mahasiswa meliputi kajian: 
(1) Kelompok kajian: pencemaran lingkungan.

(2) Kelompok kajian: kerusakan vegetasi dan hutan.

(3) Kelompok kajian: degradasi lahan dan tanah.

(4) Kelompok kajian: penurunan kualitas hidrologi.

(5) Kelompok kajian: perubahan iklim dan cuaca.

(6) Kelompok kajian: alih fungsi lahan pertanian untuk pemukiman.

(7) Kelompok kajian: daya dukung lingkungan wilayah desa dan kota.

(8) Kelompok kajian: kerusakan keanekaragaman hayati dan pesisir pantai.

Setiap kelompok mahasiswa memilih salah satu topik permasalahan lingkungan sesuai ketentuan. Mahasiswa mengumpulkan informasi masalah lingkungan yang terjadi secara kontekstual di lingkungan tempat tinggal. Mahasiswa menyusun proposal dan intrument untuk penelitian kondisi masalah lingkungan yang sudah dipilih didukung jurnal dan buku referensi. Pengumpulan data penelitian, mahasiswa melakukan investigasi dan wawancara kepada orang yang berkompeten di lingkungannya. Data hasil investigasi diolah untuk menentukan solusi dari permasalahan lingkungan dengan diskusi dan brainstroming. Solusi yang ditemukan dalam penelitian diusulkan dalam laporan penelitian yang disusun oleh setiap kelompok. Hasil penelitian dan laporan dipresentasikan kepada kelompok lain di kelas.

\section{Tabel 1. Kegiatan Perkualiahan Pendidikan Lingkungan}

\begin{tabular}{|c|c|c|}
\hline Minggu & Kegiatan & Waktu \\
\hline Minggu 1 & $\begin{array}{l}\text { Informasi konsep } \\
\text { tentang lingkungan }\end{array}$ & $\begin{array}{l}2 \text { jam } \\
\text { tatap } \\
\text { muka }\end{array}$ \\
\hline Minggu 2 & $\begin{array}{l}\text { Informasi } \\
\text { permasalahan } \\
\text { degradasi } \\
\text { lingkungan }\end{array}$ & $\begin{array}{l}2 \text { jam } \\
\text { tatap } \\
\text { muka }\end{array}$ \\
\hline Minggu 3 & $\begin{array}{l}\text { Pengantar } \\
\text { pembelajaran riset }\end{array}$ & $\begin{array}{l}2 \text { jam } \\
\text { tatap } \\
\text { muka }\end{array}$ \\
\hline Minggu 4 & $\begin{array}{l}\text { Sampel } \\
\text { pembelajaran riset }\end{array}$ & $\begin{array}{l}2 \text { jam } \\
\text { tatap } \\
\text { muka }\end{array}$ \\
\hline Minggu 5 & $\begin{array}{l}\text { Mahasiswa } \\
\text { membuat kelompok } \\
\text { penelitian }\end{array}$ & $\begin{array}{l}2 \text { jam } \\
\text { tatap } \\
\text { muka }\end{array}$ \\
\hline Minggu 6 & $\begin{array}{l}\text { Penentuan tema dan } \\
\text { pembuatan proposal } \\
\text { pembelajaran riset }\end{array}$ & $\begin{array}{l}2 \text { jam } \\
\text { tatap } \\
\text { muka }\end{array}$ \\
\hline Minggu 7 & $\begin{array}{l}\text { Penelitian } \\
\text { pengumpulan data } \\
\text { dan informasi }\end{array}$ & $\begin{array}{l}2 \text { jam } \\
\text { tatap } \\
\text { muka }\end{array}$ \\
\hline Minggu 8 & $\begin{array}{l}\text { Analisis data } \\
\text { dengan } \\
\text { brainstroming dan } \\
\text { diskusi kelompok }\end{array}$ & $\begin{array}{l}2 \text { jam } \\
\text { tatap } \\
\text { muka }\end{array}$ \\
\hline Minggu 9 & $\begin{array}{l}\text { Penulisan laporan } \\
\text { pembelajaran riset }\end{array}$ & $\begin{array}{l}2 \text { jam } \\
\text { tatap } \\
\text { muka }\end{array}$ \\
\hline $\begin{array}{l}\text { Minggu } \\
10\end{array}$ & $\begin{array}{l}\text { Presentasi } \\
\text { kelompok } 1 \text { dan } 2\end{array}$ & $\begin{array}{l}2 \text { jam } \\
\text { tatap } \\
\text { muka }\end{array}$ \\
\hline $\begin{array}{l}\text { Minggu } \\
11\end{array}$ & $\begin{array}{l}\text { Presentasi } \\
\text { kelompok } 3 \text { dan } 4\end{array}$ & $\begin{array}{l}2 \text { jam } \\
\text { tatap } \\
\text { muka }\end{array}$ \\
\hline $\begin{array}{l}\text { Minggu } \\
12\end{array}$ & $\begin{array}{l}\text { Presentasi } \\
\text { kelompok } 5 \text { dan } 6\end{array}$ & $\begin{array}{l}2 \text { jam } \\
\text { tatap } \\
\text { muka }\end{array}$ \\
\hline $\begin{array}{l}\text { Minggu } \\
13\end{array}$ & $\begin{array}{l}\text { Presentasi } \\
\text { kelompok } 7 \text { dan } 8\end{array}$ & $\begin{array}{l}2 \text { jam } \\
\text { tatap } \\
\text { muka }\end{array}$ \\
\hline $\begin{array}{l}\text { Minggu } \\
14\end{array}$ & $\begin{array}{l}\text { Penulisan artikel } \\
\text { ilmiah hasil laporan } \\
\text { pembelajaran riset }\end{array}$ & $\begin{array}{l}2 \text { jam } \\
\text { tatap } \\
\text { muka }\end{array}$ \\
\hline $\begin{array}{l}\text { Minggu } \\
14\end{array}$ & $\begin{array}{l}\text { Publikasi artikel } \\
\text { ilmiah }\end{array}$ & $\begin{array}{l}2 \text { jam } \\
\text { tatap } \\
\text { muka }\end{array}$ \\
\hline $\begin{array}{l}\text { Minggu } \\
15\end{array}$ & Evaluasi & $\begin{array}{l}2 \text { jam } \\
\text { tatap } \\
\text { muka }\end{array}$ \\
\hline
\end{tabular}


Instrument skala sikap lingkungan diimplementasikan kepada mahasiswa melalui pretest dan posttest. Sikap dan pertanyaan pendidikan lingkungan ditanyakan kepada mahasiswa dengan tiga pertanyaan terbuka. Semua pertanyaan tentang sikap pendidikan lingkungan ditanyakan dengan jawaban ya dan tidak sebelum dan sesudah implementasi pembelajaran riset dilakukan.

\section{HASIL DAN PEMBAHASAN}

\section{Analisis Kuantitatif}

Mahasiswa yang berpartisipasi sebanyak 39 dengan presentase sebesar $33,33 \%$ adalah laki-laki dan $66,67 \%$ adalah perempuan. Semua mahasiswa yang berpartisipasi adalah kelas mahasiswa semester 3. Sikap lingkungan mahasiswa diantara laki-laki dan perempuan (p: 0,125). Sebelum implementasi pembelajaran riset, mahasiswa diberikan perlakuan pre test tentang pembelajaran lingkungan dan peduli lingkungan. Hasil pre test dan distribusi presentase tentang pemahaman tentang lingkungan ditampilkan dalam tabel 2 berikut:

Tabel 2. Perilaku Sikap Mahasiswa Terhadap Lingkungan Hidup

\begin{tabular}{|l|c|c|c|}
\hline \multicolumn{1}{|c|}{ Pertanyaan } & Jawaban & $\mathrm{N}$ & $\%$ \\
\hline Apakah saudara & Ya & 9 & 23,07 \\
\cline { 2 - 4 } $\begin{array}{l}\text { sudah tahu } \\
\text { pengetahuan } \\
\text { tentang }\end{array}$ & Tidak & 30 & 76,93 \\
$\begin{array}{l}\text { lingkungan } \\
\text { sebelumnya? }\end{array}$ & & & \\
\hline
\end{tabular}

\begin{tabular}{|c|c|c|c|}
\hline \multirow[b]{2}{*}{$\begin{array}{l}\text { Apakah saudara } \\
\text { sudah tahu } \\
\text { tentang } \\
\text { dinamika } \\
\text { permasalahan } \\
\text { lingkungan } \\
\text { yang telah } \\
\text { terjadi secara } \\
\text { konstekstual? }\end{array}$} & $\mathrm{Ya}$ & 5 & 12,82 \\
\hline & Tidak & 34 & 87,18 \\
\hline \multirow[b]{2}{*}{$\begin{array}{l}\text { Apakah saudara } \\
\text { tertarik dengan } \\
\text { topik kajian } \\
\text { tentang } \\
\text { lingkungan } \\
\text { hidup? }\end{array}$} & $\mathrm{Ya}$ & 38 & 97,44 \\
\hline & Tidak & 1 & 2,56 \\
\hline \multirow[b]{2}{*}{$\begin{array}{l}\text { Apakah saudara } \\
\text { pernah terlibat } \\
\text { dalam kegiatan } \\
\text { organisasi } \\
\text { peduli } \\
\text { lingkungan? }\end{array}$} & $\mathrm{Ya}$ & 7 & 17,95 \\
\hline & Tidak & 32 & 82,05 \\
\hline \multirow[b]{2}{*}{$\begin{array}{l}\text { Apakah } \\
\text { pendidikan } \\
\text { lingkungan } \\
\text { diberikan dan } \\
\text { menjadi topik } \\
\text { pembicaraan } \\
\text { saat bersama } \\
\text { keluarga di } \\
\text { rumah? }\end{array}$} & $\mathrm{Ya}$ & 26 & 66,67 \\
\hline & Tidak & 13 & 33,33 \\
\hline \multirow[b]{2}{*}{$\begin{array}{l}\text { Apakah saudara } \\
\text { peduli dengan } \\
\text { permasalahan } \\
\text { lingkungan } \\
\text { yang terjadi di } \\
\text { sekitar tempat } \\
\text { tinggal? }\end{array}$} & $\mathrm{Ya}$ & 37 & 94,87 \\
\hline & Tidak & 2 & 5,13 \\
\hline \multirow[b]{2}{*}{$\begin{array}{l}\text { Apakah saudara } \\
\text { percaya } \\
\text { mahasiswa dan } \\
\text { guru peduli } \\
\text { terhadap } \\
\text { permasalahan } \\
\text { lingkungan? }\end{array}$} & $\mathrm{Ya}$ & 39 & 100 \\
\hline & Tidak & 0 & 0 \\
\hline
\end{tabular}

Tabel 2. menunjukkan bahwa rasio pendiidkan lingkungan mahasiswa di kelas sangat rendah hasilnya. Mahasiswa membahas topik permasalahan lingkungan yang kontekstual dengan keluarga memiliki sikap peduli 
lingkungan. Selain itu, mahasiswa menekankan pentingnya kepedulian terhadap permasalahan lingkungan bagi guru dan calon guru.

Hasil uji t-test untuk sikap peduli lingkungan (EAS) berdasarkan hasil pre test dan post test implementasi research based learning mahasiswa untuk permasalahan lingkungan dapat dilihat pada tabel 3 berikut:

Tabel 3. Hasil uji t-test Sikap Peduli Lingkungan (EAS) dengan Implementasi Pembelajaran Riset

\begin{tabular}{|l|c|c|c|c|c|c|}
\hline & $N$ & $\bar{X}$ & $s$ & $S d$ & $t$ & $p$ \\
\hline $\begin{array}{l}\text { Pre- } \\
\text { test }\end{array}$ & 39 & 61,72 & 7,62 & 38 & 30,1 & 0,00 \\
\hline $\begin{array}{l}\text { Post } \\
\text {-test }\end{array}$ & 39 & 84,2 & 8,27 & & & \\
\hline
\end{tabular}

Tabel 3 menunjukkan bahwa pembelajaran riset memberikan dampak terhadap sikap peduli lingkungan mahasiswa. Rata-rata nilai posttest mengalami peningkatan yang signifikan dibandingkan rata-rata nilai pretest. Hasil penelitian menunjukkan implementasi pembelajaran riset memberikan pengaruh yang berbeda dalam penanaman sikap peduli lingkungan kepada mahasiswa.

\section{Analisis Kualitatif}

Untuk mengidentifikasi dampak pembelajaran riset, mahasiswa diberikan pertanyaan terbuka tentang implementasi dan penggunaan pembelajaran riset dalam perkuliahan pendidikan lingkungan. Hasil evaluasi yang diberikan mahasiswa diuraikan dibawah ini:

Pertanyaan 1: Tuliskan pendapat dan pandangan saudara tentang implementasi pembelajaran riset dalam pendidikan lingkungan.

Mahasiswa memaparkan bahwa kegiatan penelitian dengan topik permasalahan lingkungan memberikan banyak informasi dari apa yang sudah diselidiki pada saat pengumpulan data di lapangan. S1 menyatakan bahwa pembelajaran riset adalah metode yang tepat untuk pembelajaran permasalahan lingkungan. Pengetahuan dan pendapat masalah lingkungan dapat untuk kajian penelitian yang diteliti. Namun, saya tidak mendapatkan banyak informasi untuk kajian penelitian diluar topik yang diteliti kelompok lain. "S10 menambahkan pernyataan berikut". Praktik pembelajaran riset pendidikan lingkungan sangat membantu dalam proses belajar mandiri secara kontekstual. Kerugian yang diterima kelompok hanya memahami topik yang menjadi fokus penelitian, sehingga informasi untuk topik lain menjadi kurang mehamai informasinya. Mahasiswa dapat menyimpulkan hasil penelitian dari hasil investigasi, diskusi, dan brainstorming dengan anggota kelompok melalui pembelajaran riset. Tindakan lingkungan 
yang dilakukan dalam kegiatan penelitian membantu meningkatkan proses berpikir kritis setiap individu. S12 memberikan argument,"Pembelajaran Riset memberikan banyak manfaat dan dapat meningkatkan informasi serta berpikirs kritis mahasiswa dalam memperoleh pengetahuan".

Komentar yang banyak diberikan, pendekatan pembelajaran riset melatih dan mengarahkan setiap individu untuk meneliti . S8 memperkuat temuan ini, bahwa pembelajaran riset mendorong kami untuk berpikir ilmiah melalui kegiatan penelitian. S15 menambahkan," kegiatan pembelajaran penelitian dengan topik memudahkan dalam proses belajar dan memperoleh informasi. S20 menjelaskan dampak positif penelitian: " proses pendidikan abad saat ini harus lebih inovatif dengan mengangkat permasalahan yang kontekstual, serta perlu dirubah metode konvensional yang secara bertahun-tahun tidak memberikan banyak manfaat dan hanya bersifat pengetahuan abstrak. Pembelajaran riset memberikan cara pandang tersendiri bagi setiap individu dalam mengkaji dan memberikan solusi. S21 berkomentar bahwa" praktik pembelajaran riset memberikan suasana pembelajaran baik untuk diskusi dan brainstorming, sehingga meningkatkan motivasi belajar kami. S26 menambahkan: "Praktik peembelajaran meneliti memberikan pengetahuan yang kompleks tentang topik kajian yang diteliti. Dengan demikian, konsep dan pengetahuan tentang topik yang diteliti memberikan pengetahuan yang baru apabila dipelajari secara menyeluruh.

Komentar dan argumentasi diatas menggambarkan bahwa pembelajaran riset memberikan dampak terhadap keterampilan berpikir kritis mahasiswa dalam memperoleh pengetahuan dari kegiatan penelitian. Kegiatan pembelajaran penelitian perlu dilakukan secara berkesinambungan sebagai inovasi pembelajaran. S18 menjelaskan manfaat penelitian: "Kami memperoleh informasi yang rinci dan kompleks dari hasil penelitian. Informasi yang baru menjadi penting untuk dipertanggung jawabkan dalam penyelesaian penelitian. Kegiatan pembelajaran riset lebih efektif dan efisien untuk meningkatkan keaktifan mahasiswa dalam pembelajaran kontekstual permasalahan lingkungan. "S6 menambahkan berikut:"Saya berkeyakinan pendidikan lingkungan tidak akan menarik jika metode pembelajarannya menggunakan metode konvensional atau lainnya. Pembelajaran riset lebih banyak memberikan waktu dan manfaat sehingga menjadi tidak 
membosankan dalam mengembangkan pengetahuan tentang pendidikan lingkungan. "S10 menyatakan pandanganya, bahwa pembelajaran penelitian dengan mengkaji topik permasalahaan lebih memberikan keterampilan berpikir dari berbagai sudut pandang.

Mahasiswa menyatakan praktik pembelajaran riset sangat menantang dan menarik untuk dilakukan. S2 menyatakan nilai praktik meneliti khusus pendidikan lingkungan meningkatkan motivasi dan minat saya. S23 menambahkan penilaian, bahwa kegiatan pembelajaran riset lebih mudah dipahami informasi pengetahuannya. S28 mengomentari dampak positif pembelajaran riset: "kegiatan penelitian dengan kajian permasalahan lingkungan dapat dikembangkan dengan cara menyenangkan mencakup kegiatan mengembangkan teori dari buku dan jurnal, kegiatan penelitian, serta diskusi dan brainstorming. Kegiatan pembelajaran menjadi kurang menarik dan tidak efektif jika pembelajaran dengan metode terfokus pada dosen.

\begin{tabular}{lrr}
\multicolumn{2}{c}{ Mahasiswa juga } & memberikan \\
pendapat & negatif & pendekatan \\
pembelajaran & riset: & Kegiatan \\
pembelajaran dan & riset & belum familiar \\
bagi & mahasiswa. & Implementasi
\end{tabular}

pembelajaran riset belum pernah dilakukan sebelumnya mengingat mahasiswa masih terbiasa dengan metode konvensional. Aplikasi penelitian lebih bermanfaat dan menyenangkan dalam mengembangkan pengetahuan kognitif, afektif, dan psikomotorik mahasiswa.

Pertanyaan 2: Apakah kesulitan yang saudara rasakan pada saat implementasi pembelajaran riset untuk pendidikan lingkungan?

Kesulitan yang dialami dari implementasi pembelajaran penelitian, mahasiswa menyatakan bahwa kesulitan research based learning diantaranya, pemahaman metode dan teknik meneliti, penulisan saran dan laporan yang sulit, kerjasama kelompok yang kurang, informasi data penelitian sulit untuk dipecahkan agar mendapatkan solusi terbaik. S7 menjelaskan bahwa kesulitan dari kegiatan pembelajaran penelitian pada awalnya yaitu mengembangkan topik kajian masalah lingkungan menjadi proposal penelitian dengan ide-ide yang inovatif. S22 menambahkan, "bahwa permasalahan terbesarnya adalah kegiatan implementasi pembelajaran peneletian ini baru pertama dilakukan. "S32 memaparkan aspek negatif implementasi dari kegiatan pembelajaran penelitian memberikan keraguan dalam diri sendiri untuk menyelesaikan laporan penelitian, 
tetapi setelah selesai penyusunan laporan penelitian hasilnya menjadi pengalaman yang berharga dalam memperoleh pengetahuan dan informasi.

Selain itu, mahasiswa mengalami kesulitan dalam menulis saran dan laporan kelompok. S9 memaparkan kesulitan yang dihadapi dalam memberikan saran dari hasil penelitian yang sudah disusun. Ides-ide yang diberikan dari diskusi kelompok tidak dapat diaplikasikan untuk pendidikan lingkungan secara berkelanjutan meskipun sudah mencapai kesimpulan. S2 memiliki pandangan yang sama, menambahkan bahwa,"kami mengalami kesulitan besar dalam implementasi pembelajaran riset sesuai ide-ide dalam penyelesain laporan.

Kegiatan pembelajaran riset menyita waktu dan pekerjaan intensif. S4 menyatakan tentang sifat pendekatan ini: "Kami tidak dapat memperoleh informasi dengan mudah sesuai keinginan. Hal ini banyak membutuhkan waktu dalam analisis informasi. S23 juga menambahkan gambaran bahwa,"Kami kesulitan dalam mengoptimalkan waktu secara efektif dalam menggali informasi penelitian".

Mahasiswa mengalami kendala dalam kerja kelompok. S14 menyatakan bahwa kegiatan kerja kelompok memberikan kesulitan dalam pembagian tugas kegiatan penelitian dari awal sampai akhir". S29 menambahkan, "Kelompok mengalami kesulitan dalam berkumpul untuk menyelesaikan laporan penelitian. Namun demikian, kegiatan kerja kelompok sangat memudahkan dalam pengumpulan informasi yang kompleks dari hasil penelitian.

Mahasiswa juga menyatakan bahwa kesulitan yang dihadapi saat penelitian adalah menemukan informasi yang sesuai dengan topik kajian kelompoknya. Kebijakan dari pihak berwenang memberikan dampak bagi kelompok dalam memecahkan permasalahan yang kompleks. Dampaknya mahasiswa tidak dapat mengembangkan penelitian dengan objek kajian yang lebih berkelanjutan tentang permasalan lingkungan S28 melaporkan bahwa permasalahan yang dihadapi saat penelitian adalah kurangnya wawasan pengetahuan lingkungan. Namun, hasil wawancara kepada responden dapat sesuai dengan topik kajian penelitian.

Pertanyaan 3: Apakah implementasi pembelajaran riset dapat digunakan untuk perkuliahan di bidang lain ?

Mahasiswa memberikan tanggapan positif dan negatif terhadap pertanyaan tersebut. Pandangan negatif mahasiswa bahwa pembelajaran riset tidak sesuai untuk semua disiplin ilmu, selain itu 
laporan hanya terbatas pada informasi penelitian sehingga dampaknya tidak semua individu menyukai kerja kelompok. Pembuatan laporan menjadi ide yang baik, termasuk publikasi ilmiah dari hasil penelitian.

Disisi lain, tanggapan positif dari mahasiswa bahwa pembelajaran riset sangat menyenangkan, menarik, dan memberikan keleluasaan dalam bersosiasilasi melalui kegiatan pembelajaran penelitian. Mahasiswa merasakan pembelajaran menjadi lebih aktif, kreatif, dan mempengaruhi sikap berpikir kritis dalam diskusi dan brainstorming. S1 menyatakan pendapat bahwa pembelajaran riset sangat cocok untuk semua matakuliah. Topik kajian masalah menjadi fokus utama dalam implementasi penelitian. S16 tidak setuju menjelaskan, "Saya meyakini metode ini tidak cocok untuk semua disiplin ilmu". S8 menambahkan, "Saya tidak yakin pembelajaran dan riset ini dapat digunakan untuk semua disiplin ilmu karena merupakan latihan yang membutuhkan waktu lama. Metode ini dapat digunakan untuk matakuliah yang sesuai dengan pembelajaran kontekstual karena memberikan manfaat yang nyata bagi mahasiswa. Banyak komentarkomentar yang diungkapkan bahwa pembelajaran riset tidak sesuai dalam efisiensi waktu. S23 memberikan kritik, "Implementasi pembelajaran riset memerlukan waktu sangat lama untuk menyiapkan proposal, kegiatan penelitian, pengolahan data, dan pembuatan laporan penelitian, sehingga tidak sesuai untuk perkuliahan pada matakuliah dan disiplin ilmu lainnya.

Pandangan negatif mahasiswa yang diungkapkan bahwa pembelajaran konvensional sudah menjadi tradisi bertahun-tahun selama ini. Mahasiswa banyak mengeluh banyak waktu yang dihabiskan untuk kegiatan penelitian yang intensif. Saran yang diberikan mahasiswa agar pembelajaran riset lebih dikembangkan untuk penelitian yang lebih kreatif. S7 menyatakan persetujuannya:" Ya, Saya menyukai kegiatan penelitian karena melatih untuk berpikir kritis, meneliti, menulis, dan $\begin{array}{lll}\text { berpikir ilmiah. } & \text { S13 }\end{array}$ menambahkan,'Pembelajaran riset meningkatkan kreativitas mahasiswa, tetapi setiap kelompok hanya terfokus pada kajian permasalahan penelitiannya saja”. S34 mengomentari dampak positif pembelajaran riset:'Implementasi pendekatan dan metode ini mengarahkan mahasiswa untuk berkumpul diskusi dan brainstorming untuk menghasilkan ideide yang kreatif dan inovatif". Kerangka 
kerja yang jelas memberikan keleluasaan dalam memberikan gagasan.

Mahasiswa percaya bahawa
pembelajaran riset memberikan
pembelajaran yang sangat efektif. S37
mengungkankan keingginannya agar
metode ini diimplementasikan pada
matakuliah dan disiplin ilmu
lainnya:"Saya ingin pendekatan ini

digunakan untuk matakuliah dan disiplin ilmu lain yang kajian materinya bersifat kontekstual karena cara belajarnya yang efektif. S17 menambahkan, $\begin{array}{lrr}\text { "Pembelajaran } & \text { riset } & \text { sangat } \\ \text { menguntungkan } & \text { karena } & \text { bersifat }\end{array}$ kolaboratif dan terfokus pada mahasiswa. Manfaat yang diperoleh oleh mahasiswa dapat digunakan untuk menjawab pertanyaan penelitian yang sedang dipecahkan dari hasil investigasi dan analisis secara kelompok.

Mahasiswa menyatakan puas
implementasi pembelajaran riset meningkatkan perkuliahan menjadi lebih aktif. S9 menyatakan,'Pembelajaran riset adalah metode yang berpusat pada mahasiswa. Saya merasakan metode ini sesuai dengan bahan kajian dan subjek perkuliahan. Metode ini menyenangkan karena memberikan kemudahan dalam peningkatan diskusi dan brainstorming secara kooperatif yang dapat memberikan persaingan antarkelompok. Saya merasakan metode ini lebih memperkuat kemauan diri saya untuk belajar".S26 mengiyakan pujian itu,"Ya, karena semua mahasiswa berupaya secara mandiri dalam menyelesaikan permasalahan melalui kegiatan penelitian untuk mendapatkan gagasan serta solusi yang terbaik dan efisien. S31 menambahkan,"Saya merasakan metode ini dapat memberikan efek yang positif dalam berkomunikasi dalam proses analisis hasil penelitian. Pembelajaran ini merupakan yang terbaik dilakukan baik secara kelompok atau individu". Selain itu, mahasiswa harus selalu siap dalam implementasi metode ini khususnya untuk setiap individu.

Berdasarkan hasil penelitian menunjukkan tidak ada perbedaan sikap peduli lingkungan mahasiswa dalam konteks gender. Temuan Ozay-Kose (2010), bahwa tidak ada perbedaan sikap peduli lingkungan diantara laki-laki dan perempuan. Temuan berbeda dari (Erol \& Gezer, 2006; McCright, 2010; Larson, Castleberry, \& Green, 2010; GurbuzogluYalmanci \& Gozum, 2011; Sundstrom \& McCright, 2013), bahwa perempuan memiliki sikap peduli lingkungan yang lebih baik dibandingkan laki-laki. Hasil study Carrier (2009), menememukan bahwa pendidikan lingkungan lebih banyak dilakukan oleh laki-laki 
dibandingkan perempuan di halaman sekolah. Sikap peduli lingkungan laki-laki banyak mengadopsi dari kepedulian lingkungan perempuan. Perubahan perilaku pada setiap individu berorientasi pada pendidikan lingkungan berkelanjutan. (Tidball \& Krasny, 2011), menyatakan peran manusia dalam bereksplorasi terhadap ekosistem mempengaruhi sistem sosial ekologis dalam pendidikan lingkungan. Elemen pendidikan menjadi kunci utama dalam pendidikan berkelanjutan bagi mahasiswa agar lebih memiliki sikap peduli lingkungan. Kesiapan guru memiliki peran dalam pendidikan lingkungan secara terpadu (Esa, 2010). Sikap peduli lingkungan mahasiswa terkait alam dipengaruhi pengetahuan dan permasalahan lingkungan yang saling berhubungan (Tikka, Kuitunen, Tynnys, 2000).

Pembelajaran riset pendidikan lingkungan menarik minat mahasiswa untuk berpikir kritis dan inovatif. Yeoman \& Zamorski (2008), pembelajaran riset menghubungkan kegiatan pembelajaran penelitian dengan lingkungan akademik.

Keterlibatan mahasiswa dalam kegiatan penelitian memungkinkan pembangunan variasi pengetahuan di berbagai disiplin ilmu yang lebih inoatif (Healey, 2005; Healey, Jenkins, \& Lea, 2014) Implementasi pembelajaran riset memberikan rangsangan kepada mahasiswa dan dosen (Sproken-Smith \& Walker, 2010). Pembelajaran riset dapat mengembangkan antusiasme penelitian, berpikir kritis dan kreatif kepada mahasiswa (Guinness, 2012). Perkuliahan dengan mengggunakan riset dapat melatih kemampuan metakognitif mahasiswa dalam berpikir kritis, membuat prediksi, menguraikan faktor-faktor penyebab, dan menyajikan argumentasi yang konstruktif dengan diukur dari komponen presentasi dan laporan ilmiah (Al-Maktoumi, AlIsmaily dan Kacimov, 2016). Keunggulan pembelajaran riset perlu aplikasi secara berkelanjutan untuk bidang lainnya. Perluasan implementasi pembelajaran riset perlu diterapkan di banyak jurusan dengan tujuan untuk menerapkan penelitian dalam pendidikan serta menghubungkan penelitian dan pengajaran (Schapper \& Mayson, 2010). Hasil penelitian Li (2013), permasalahan dalam pendidikan lingkungan dipengaruhi pelatihan guru yang terbatas, kurikulum yang tidak berkembang dan kebijakan administrasi yang lambat. Dinamika yang terjadi kegiatan pendidikan lingkungan perlu adanya keberlanjutan bagi mahasiswa. Keles, Uzun, \& VarnaciUzun (2010), menentapkan bahwa pendidikan lingkungan memberikan pengaruh yang signifikan terhadap 
kesadaran, sikap, dan perilaku individu secara berkelanjutan.

Hasil studi May (2000) bahwa kondisi pendidikan, kompetensi guru, dan praktik mengajar memiliki peran penting dalam pendidikan lingkungan. Keterlibatan mahasiswa dalam proyek permasalahan lingkungan berdampak positif terhadap pengetahuan dan sikap sains (Al-Balushi \& Al-Aamri, 2014). Pembelajaran riset mempengaruhi sikap mahasiswa dalam berintekasi dengan lingkungan dan masyarakat. Kepedulian dari setiap individu terhadap permasalahan lingkungan diperlukan secara berkelanjutan melalui jenjang pendidikan. Hubungan masalah sosial dan ekologis dalam pembangunan berkelanjutan dipengaruhi oleh kesadaran, konfirmasi, dan kolaborasi dari guru (Villanen, 2014). Guru memiliki pengaruh yang penting dalam mendidik anak-anak dan remaja menjadi pemimpin masa depan untuk advokasi lingkungan (Esa, 2010). Peran guru yang penting dalam pendidikan lingkungan dipengaruhi oleh metode proses pembelajaran yang efektif dan inovatif sesuai permasalahan yang kontekstual dari kehidupan. Implementasi pembelajaran riset dipengaruhi komponen manajemen instruksional berbasis penelitian, karakteristik guru dan perilaku mahasiswa, indikator hasil dan pencapaian guru, keterampilan dan karakteristik yang diperlukan mahasiswa (Poonpan \& Suwanmankha, 2005). Metode yang efektif dan aktif secara otomatis akan memberikan sikap peduli lingkungan kepada mahasiswa. Pendidikan lingkungan yang berkelanjutan diperlukan bagi mahasiswa sebagai proses transformasi (Tal, 2010).

\section{KESIMPULAN}

Sikap peduli lingkungan mahasiswa tidak dipengaruhi perbedaan gender antara laki-laki dan perempuan. Fakta dan konsep membantu mahasiswa dalam mengintegrasikan sikap peduli lingkungan dengan pendekatan pembelajaran riset. Turner et al. (2009) menegaskan bahwa pemahaman mahasiswa dapat tercapai ketika dosen memiliki pengetahuan tentang lingkungan. Tujuannya untuk menghindari resiko mengarahkan mahasiswa tentang masalah lingkungan (Spiropoulou et.al., 2007). Sikap positif terhadap lingkungan diperoleh setelah melakukan kegiatan penelitian, sehingga dapat mengkaji permasalahan lingkungan yang kontekstual secara kritis melalui analisis, diskusi, dan brainstorming. Pembelajaran riset dapat membantu mendeskripsikan permasalahan dan solusi terbaik dari proyek yang akan diselesaikan. Permasalahan yang 
kontekstual memberikan perubahan pola berpikir pada mental sikap peduli lingkungan mahasiswa. Mahasiswa dapat membangun koneksi intelektual secara praktis sesuai batas-batasan potensi yang kuat dari belajar mandiri (Baldwin, 2005). Peran guru menjadi penting dalam inovasi

\section{E. DAFTAR PUSTAKA}

Al-Balushi, Sulaiman M \& Al-Aamri, Shamsa S.(2014). The Effect of Environmental Science Projects on Students' Environmental Knowledge and Science Attitudes, International Research in Geographical and Environmental Education, 23 (3), 213-227.

Al-Maktoumi, Ali, Al-Ismaily, Said, \& Kacimov, Anvar.(2016). Research Based Learning for Undergraduate Students in Soil and Water Sciences: a case Study of Hydropedology in an Arid Zone Environment, Journal of Geography in Higher Education, Vol.40, 1-19.

Baldwin, G.(2005). The Teaching Research Nexus: How Research Informs and Enhances Learning and Teaching in University of Melbourne. Melbourne: The University of Melbourne.

Balim, A.G.(2013). The Effect of Mind Mapping Applications on Upper Primary Student Success and Inquiry Learning Skills in Science and Environment Education. International Research in Geographical and Environmental Education, 22 (4), 337-352.

Barnett, M., Vaughn, M.H., Strauss, E., and Cotter, L. (2011). Urban pembelajaran untuk pendidikan lingkungan bagi mahasiswa. Untuk itu guru perlu mendorong sikap peduli lingkungan mahasiswa secara aktif berkelanjutan ke masa depan sesuai dinamika perkembangan ilmu pengetahuan dan sains.

Environmental Education: Leveraging Technology and Ecology to Enggage Student in Studying the Environment, International Research in Geographical and Environmental Education, 20 (3), 199-214.

Baxte, P and Jack, S.(2008). Qualitative Case Study Methodology. Study Design and Implementation fo Noice Researchers. The Qualitative Report, 13 (4), 544-559.

Berberoglu, G \& Tosunoglu, C.(1995). Exploratory and Confirmatory Factor Analyses of an Environmental Attitude Scale (EAS) for Turkish University Students, Journal of Enironmental Education, 26 (3), 40 44.

Blackmore, P. and Fraser, M.(2007). Researching and Teaching. UK: McGraw-Hill International.

Brew, A.(2010). Imperative and Challenges in Integrating Teaching and Research, Higher Education Research \& Development, 29, 139150.

Carrier, S.J.(2009). Environmental Education in the Schoolyard: Learning Styles and Gender, The Journal of Environmental Education, $40(3), 2-12$.

Cetin-Dindar, Ayla.(2016). Student Motivation in Constructivist Learning Environment, Eurasia Journal of 
Mathematics, Science \& Technology Education, 12 (2), 233-247.

Creswell, John W.(2009). Research Design Qualitative, Quantitative, and Mixed Methods Approaches (3eds.). California: SAGE publications.

Daskolia, M., Dimos, A., and Kampylis, P.(2012). Secondary Teacher's Conceptions of Creative within the Context of Environmental Education, International Journal of Environmental \& Science Education, 7 (2), 269-290.

Drake, L.(2004). Mind in Society: The Development of Higher Psychological Processes. Cambridge: Havard University Press.

Erol, G.H., \& Gezer, K.(2006). Prospective of Elementary School Teachers's Attitude Toward Environment and Environmental Problems, International Journal of Environmental and Science Education 1, 65-77.

Esa, Norizan.(2010). Environmental Knowledge, Attitude and Practices of Student Teachers, International Research in Geographical and Environmental Education, 19(1), 3950.

Fraenkel, J.R., Wallen, N.E., \& Hyun, H.H.(2012). How to Design and Evaluate Research in Education (8th ed.). New York: The McGraw-Hill Companies.

Guinness, Patrick.(2012). Research Based Learning: Teaching Development Through Fieldschools, Journal of Geography in Higher Education, Vol 36, No. 3, 329-339.

Gurbuzoglu-Yalmanci, S., \& Gozum, A.I.C.(2011). The Inventigation of Kafkas Uniersity of Candidate
Teachers' Attitudes Towards Environmental Problem with Respect to same Variables, International Online Journal of Educational Sciences, 3(3), 1109-1132.

Healey, M.(2005). Linking Research and Teaching to Benefit Student Learning, Journal of Geography in Higher Education, 29, 183-201.

Healey, M., Jenkins, A., \& Lea, J.(2014). Developing Research Based Curricula in College Based Higher Education. New York: The Higher Education Academy.

Hmelo-Silver, C.E., and Barrows, H.S.(2006). Goals and Srategies of a Problem Based Learning Facilitator. Interdisciplinary Journal of Problem Based Learning 1(1), 21-39.

Kadji C.2002.Evaluation of Whole School Environmental Education, Kansas Association for Conservation and Environmental Education. Available at: www.kacee.org (Accesses October 2017).

Keles, O., Uzun, N, Varnaci-Uzun, F.(2010). The Change of Teacher Candidates' Environmental Consciouness, Attitude, thought and Behaviours with Nature Training Project and the Assessment of Its Performance, Elektronic Journal of Social Science, 9(32), 384-401.

Kilinc, A. (2010). Can Project Based Learning Close the Gap ? Turkish Student Teachers and Proenvironmental Behaviours. International Journal of Environmental \& Science Education, 5(4), 495-509.

Larson, Lincoln R., Castleberry, Steven B. \& Green Gary T.(2010). Effects of an Environmental Education Program 
on the Environmental Orientations of Children from Different Gender, Age, and Ethnic Groups, Journal of Park and Recreation Administration, 28 (3), 95-113

Leech, N.L \& Onwuegbuzie, A.J.(2009). A Typology of Mixed Methods Research Designs. Springer, 43: 265275. DOI 10.1007/s11135-007-91053.

Li, J.(2013). Environmental Education in China's College English Context: A Pilot Study, International Research in Geographical and Environmental Education, 22(2), 139-154.

Liu, Xiaolai and Li, Qinghuai. (2011). Combination of the Research Based Learning Method with the Modern Physics Experiment Cource Teaching, International Education Studies, Vol 4, No 1, 101-104.

Markaki, V.(2014). Environmental Education through Inquiry and Technology. Science Education International, 25 (1), 86-92.

May, T.S. (2000). Elements of Success in Environmental Education through Practitioner Eyes, Journal of Environmental Education, 31 (3), 411.

McCright, Aaron M.(2010). The Effects of Gender on Climate Change Knowledge and Concern in the American Public, Population and Environment 32(1), 66-87.

Oweini, A. and Houri, A. (2006). Factors Affecting Environmental Knowledge and Attitudes among Lebanese College Students. Applied Environmental Education and Communication, 5, 95-105.

Ozay-Kose, E.(2010) The Factors that Affect Attitudes Towards
Environment of Secondary School Student, Journal of Turkish Science Education, 7(3), 198-211.

Rickinson, M. (2001). Learners and Learning Environmental Education: A critival review of the evidence, Environmental Education Research, 7 (3), 207-320.

Scahpper, J \& Mayson, E.S.(2010). Research-led Teaching: Moving from a Fractured Engagement to a Marriage of Convenience, Higher Education Research \& Development, 29, 641651.

Shepardson, Daniel P., Wee, Bryan, Priddy, Michelle, and Harbor, Jon.(2007). Student' Mental Models of the Environment, Journal of Research in Science Teaching, Vol. 44, No. 2, PP. 327-348.

Spiropoulou, D., Antonakaki, T., Kontaxakaki, S. \& Bouras, S.(2007). Primary Teachers' Literacy and Attitudes on Education for Sustainable Development, Journal of Science Education and Technology, 16, 443-450

Srikoon, Sanit, Bunterm, Tassanee, Samranjai, Jakkrit, and Wattanathorn, Jintanaporn. (2013). Research Synthesis of Research Based Learning for Education in Thailand, ProcediaSocial and Behavioral Sciences 116 (2014), 913-917.

Sproken-smith, R \& Walker, R (2010). Can Inquiry Based Learning Strengthen the Links Between teaching and Discipinary Research?, Studies in Higher Education, 35, 723740.

Sundstrom, Aksel \&Mccright, Aaron M.(2013). Examining Gender Differences in Environmental 
Concern Across Four Levels of the Swedidh Polity, Working Paper Series 2013: 10, University of Gothenburg.

Tal, T.(2010). Pre-service Teachers' Reflections on Awareness and Knowledge Following Active Learning in Environmental Education, International Research in Geographical and Environmental Education, 19 (4), 263-276.

Taskin, O.(2005). An Evaluation of the Studies on Environmental Attitude and Knowledge, Education and Science, 30 (138), 78-85.

Teddlie, Charles and Yu, Fen.(2007). Mixed Methods Sampling: A Topology with Examples, Journal of Mixed Methods Research, Vol. 1. (1), 77-100, Sage Publications.

Tidball, Keith G \& Krasny, Marianne E..(2011). Toward an Ecology of Environmental Education and Learning, Ecosphere, Vol. 2(2), 1-17.

Tikka, Paivi M., Kuitunen, Markku T. \& Tynnys, Salla M. (2000). Effects of Educational Background on Students' Attitudes, Activity Levels, and Knowledge Concerning the Environment, The Journal of Environmental Education, 31(3), 21 19.

Turner, G., Tekkaya C., Sungur, S., Cakiroglu, J., Ertepinar, H., \& Kaplowitz, M.(2009). Assessing preservice Teachers' Environmental Literacy in Turkey as a mean to Deelop Teacher Education Programs, International Journal of Educational Development, 29, 426-436.

Villanen, Heli.(2014). Teachers' Reflections on an Education Sustainable Development Project,
International Research in Geographical and Environmental Education, 23 (2), 179-191.

Watson, $\mathrm{K}$ and Halse, C.M.(2005). Environmental attitudes of preservice teachers: A conceptual and methodological dilemma in crosscultural data collection. Asia Pasific Education Review, 6 (1), 59-71.

Yeoman, K.H., \& Zamorski, B. (2008). Investigating the Impact on Skill Development of an Undergraduate Scientific Research Skills Cource, Bioscience Education, 5-11. 